\section{DA CRÍTICA À METAFÍSICA À METAFÍSICA CRÍTICA ${ }^{1}$}

\author{
Gabriel Martins Ferreira \\ Graduando pela UnB
}

\begin{abstract}
Resumo: Tomando por fio condutor uma importante questão para a teoria do conhecimento na filosofia moderna, a saber, é possivel um conhecimento racional da realidade? $\mathrm{O}$ presente trabalho tem por objetivo analisar um importante debate realizado no século XVIII entre David Hume e Immanuel Kant na tentativa de dar resposta a esta pergunta. De modo que num primeiro momento nos ocuparemos com a objeção humeana aos procedimentos adotados pela tradição metafísica nas Investigações sobre o entendimento humano. Após apresentar a objeção de Hume, concentrar-nos-emos em apresentar o modo pelo qual Kant por um lado, recepciona a crítica feita por Hume, e por outro recusa as conclusões humeanas conduzindo o problema com vistas a oferecer uma resposta mais sistemática.
\end{abstract}

Palavras-chave: Kant; Hume; Conhecimento; Empirismo; Hábito; Crítica

\begin{abstract}
This research aims to analyze an important question for modern philosophy, namely, is it possible a rational knowledge of reality? To accomplish this goal, the present work analyzes the debate between David Hume and Immanuel Kant around the answer of the question above mentioned. Then, we divide this analysis in two parts: in the first we deal with David Hume's objections to the metaphysical tradition procedures presented in his work An Enquiry Concerning Human Understanding. Right after we present the way through which Kant accept the Hume's objection; after this, we will discuss why according to Kant would be necessary an analysis more systematic to offer, then, a satisfactory answer to the problem.
\end{abstract}

Keywords: Kant; Hume; Knowledge; Empiricism; Habit; Critique
Orientados por uma pergunta que norteia o debate acerca da possibilidade do conhecimento na filosofia moderna - como conhecemos racionalmente algo? -, o presente trabalho pretende explorar aquilo que se converteu em uma espécie de lugar comum na compreensão dos estudiosos em torno da mencionada questão, a saber, o debate entre David Hume e Immanuel Kant. Mais precisamente, a presente pesquisa tem por fio condutor "o despertar do sono dogmático", que, de acordo com o próprio Kant, os argumentos de Hume o teriam incitado. Para tanto, tomaremos o modo pelo qual Kant responde à objeção posta por Hume (qual seja: de que é impossível o conhecimento a priori do real e, portanto, a impossibilidade da metafísica como ciência do real), e como, na visão de Kant, embora Hume tivesse fornecido um argumento irrefutável, por outro lado, como parte da resposta ao problema fundamental do conhecimento, seria necessário conduzir a resposta de modo mais sistemático, o que implica fazer um exame prévio das condições da razão pura para tal conhecimento, isto é, se ela possui ou não a capacidade de conhecer a priori: eis a chave para a compreensão da filosofia transcendental de Kant.

\section{I-A Objeção de Hume à Metafísica}

A objeção humeana à metafísica e seus procedimentos contidas nas Investigações sobre o entendimento humano (doravante Investigações) podem ser entendidas em um duplo movimento de um mesmo argumento, a saber, (I) ela apresenta a significação empírica das ideias e (II) destitui o caráter a priori do princípio de causalidade. A partir disso Hume conclui que um conhecimento a priori seria impossível bem como - como corolário - a cientificidade da metafísica.

O primeiro movimento do argumento humeano é apresentado na seção II das Investigações

\footnotetext{
${ }^{1}$ Texto apresentado como Relatório Final do PIBIC 2015\2016 com apoio financeiro da FAP-DF.
} 


\section{Gabriel Martins Ferreira}

sobre o entendimento humano intitulada "Da Origem das Ideias". O filósofo inglês distingue aquilo que segundo ele são "as percepções da mente" em duas classes, as impressões e as ideias, segundo "os seus graus de força e vivacidade" (HUME, 2004, p.34). As primeiras são de acordo com Hume "nossas percepções mais vívidas", ao passo que as ideias são "as menos fortes e vivazes", concebidas a partir das impressões; em outras palavras, as ideias são cópias das impressões. ${ }^{2}$ A partir deste argumento, a conclusão de Hume é que sempre que quisermos saber o significado de uma ideia devemos perguntar de que impressão provém tal ideia, "mesmo aquelas ideias que, à primeira vista, parecem as mais afastadas dessa origem revelam-se, após uma exame mais detido dela [das impressões] derivadas" (HUME, 2004, p. $36)^{3}$

Explicada então a origem das ideias, o segundo movimento do argumento humeano é apresentar o modo pelo qual o entendimento associa as ideias. Segundo o filósofo, as associações de ideias obedecem a três princípios, quais sejam, o de semelhança, contiguidade e causalidade. Para os fins pretendidos por esta pesquisa, interessa-nos aqui apenas o princípio de causalidade, pois é a este princípio que Hume dirige sua crítica e que também o levará a concluir pela impossibilidade de um conhecimento a priori da realidade, o que equivale dizer que a metafísica não poderia ser uma ciência tal como pensada pela tradição.

No início da seção IV das Investigações, Hume opera uma distinção entre os objetos da razão, a saber, entre relações de ideias e questões de fato. De acordo com o filósofo:
Do primeiro tipo [as relações de ideia] são as ciências da geometria, álgebra e aritmética, e, em suma toda afirmação que é intuitivamente certa... Proposições deste tipo podem ser descobertas pela simples operação do pensamento, independente do que possa existir em qualquer parte do universo. Mesmo que jamais houvesse existido um círculo ou triângulo na natureza, as verdades demonstradas por Euclides conservariam para sempre sua certeza. (HUME, 2004, p.53)

Porém, com relação às questões de fato a posição adotada por Hume é diametralmente oposta. Segundo Hume:

Questões de fato, são o segundo tipo de objetos da razão humana, não são apuradas da mesma maneira, e tampouco nossa evidência de sua verdade, por grande que seja é da mesma que a precedente. $O$ contrário de toda questão de fato permanece sempre sendo possivel, porque não pode jamais implicar contradição, e a mente a concebe com a mesma facilidade e clareza, como algo perfeitamente ajustável à realidade. (HUME, 2004, pp. 53-54. Grifo nosso)

Desta comparação, poder-se-ia inferir que o domínio do conhecimento a priori está restrito unicamente ao domínio das relações de ideia (consequentemente, apenas a matemática poderia reivindicar universalidade e necessidade de seus juízos), uma vez que neste domínio as inferências seriam regulamentadas por princípios meramente lógicos, por exemplo, o princípio de não-contradição. No que concerne às questões de fato, isto é, ao nosso conhecimento acerca do mundo, segundo Hume "todos os nossos raciocínios referentes a questões de fato parecem fundar-se na relação de causa e efeito" (HUME, 2004, p.54). O princípio de causalidade, segundo a perspectiva humeana, não é de modo algum "alcançado por

\footnotetext{
${ }^{2}$ Toda esta argumentação se encontra nas. Investigações. pp.34-36.

${ }^{3}$ Termos entre colchetes foram adicionados por mim.
} 


\section{Gabriel Martins Ferreira}

meio de raciocínios a priori, mas provém inteiramente da experiência" (HUME, 2004, p. 55); e uma vez que Hume sustenta que "todo efeito é um acontecimento distinto de sua causa", então "[o efeito] não poderia, por isso mesmo, ser descoberto na sua causa" (HUME, 2004, p.59). Se o princípio de causalidade não é fruto de uma operação do pensamento e tampouco é alcançado por raciocínios a priori, qual o verdadeiro caráter do princípio de causalidade?

$\mathrm{L}$

A razão é incapaz de variar dessa forma; as conclusões que ela retira da consideração de um único círculo são as mesmas que formaria após inspecionar todos os círculos do universo. Mas, nenhum homem, tendo visto apenas um único corpo mover-se após ter sido impelido por outro, poderia inferir que todos os corpos mover-se-iam após um impulso semelhante. Todas as inferências da experiência são, pois, efeitos do hábito, não do raciocínio. (HUME, 2004, p.75)

$\mathrm{Na}$ parte 2 da seção IV das Investigações, Hume coloca três questões, quais sejam, (I) qual é a natureza de todos os nossos raciocínios acerca de questões de fato? (cuja resposta é o princípio de causalidade, conforme já explicado); (II) qual é o fundamento de todos os raciocínios e conclusões acerca desta relação, isto é, do princípio de causalidade? (a resposta, conforme apresentada acima, é a experiência); (III) qual é o fundamento de todas as conclusões a partir da experiência? A resposta a esta questão, no entanto, é oferecida por Hume da seção $\mathrm{V}$ das Investigações. Segundo o filósofo "todas as inferências da experiência são, pois, efeitos do hábito, não do raciocínio" (HUME, 2004, p.75). O hábito enquanto um princípio regulador de nossas conclusões a partir da experiência faz com que "de causas que aparecem semelhantes, esperamos efeitos semelhantes" (HUME, 2004, p.66).

Daí a conclusão segundo a qual, uma vez estabelecido que conhecimento da experiência é fruto de um dispositivo psicológico de associação irrefletida - o hábito -, Hume inviabiliza a possibilidade de um conhecimento a priori da experiência, já que não haveria a possiblidade de, por meio de meros procedimentos lógicos (como é o caso com o princípio de causalidade, por meio do qual visou-se a inferir o antecedente logicamente do consequente), concluir um conhecimento regular dos eventos empíricos, restringindo este conhecimento apenas ao domínio das relações de ideias. Nesse ínterim, a metafísica, enquanto suposta ciência que sempre pretendeu estabelecer um conhecimento a priori da experiência, é inviabilizada pela proposta de Hume.

\section{II - A resposta de Kant}

Em uma célebre passagem no prefácio aos Prolegômenos a Qualquer Metafisica Futura Que Queira Apresentar-se como Ciência (doravante Prolegômenos), Kant atribui a Hume o fato de o ter despertado de seu sono dogmático. Assim, nesta segunda parte desta pesquisa, interessa-nos compreender em que consiste este "despertar". Embora Kant, por um lado, aceite a objeção interposta por Hume (qual seja: de que de meros procedimentos lógicodedutivos não se alcança um conhecimento a priori da realidade); por outro lado, como parte da resposta ao problema fundamental do conhecimento, seria necessário conduzir a resposta de modo mais sistemático, o que implica fazer um exame prévio das condições da razão pura para tal conhecimento, isto é, se ela possui ou não a capacidade de conhecer a priori.

A primeira exigência para responder ao problema fundamental da razão foi apresentada 


\section{Gabriel Martins Ferreira}

pela Crítica da Razão Pura de Kant na parte denominada Estética Transcendental, qual seja, que um objeto possa ser intuído no espaço e no tempo. "A intuição e os conceitos, portanto, constituem os elementos de todo o nosso conhecimento"4, diz Kant. Se por um lado Kant estabelece ali o tempo e o espaço como condições formais de qualquer percepção a priori do objeto ${ }^{5}$, por outro, resta ainda estabelecer quais são os conceitos que determinam nosso conhecimento, o que é tarefa daquilo que os comentadores chamam de Dedução Metafisica. ${ }^{6}$

A Dedução Metafísica atende na $\mathrm{KrV}$ pelo nome de "Do Fio Condutor Para a Descoberta de Todos os Conceitos Puros do Entendimento". Para além de qualquer análise mais esmerada de cada um dos passos seguidos por Kant na mencionada dedução, o que mais nos interessa aqui é estabelecer um fio condutor que nos permita compreender o modo pelo qual Kant estabelece sua tábua de categorias a partir da função judicativa do entendimento.

Juízo na acepção kantiana nada mais é que "a representação da unidade da consciência de diversas representações ou a representação da relação entre elas, na medida em que constituem um conceito" (KANT, 2014, p. 201). O entendimento (humano) para Kant possui uma única função, a saber, pensar (denken), que na terminologia kantiana significa "unir representações em uma consciência".7 Assim, o primeiro passo da
Dedução Metafísica é o de exaurir o entendimento apresentando o(s) modo(s) como este pensa (ou julga) um objeto, nomeadamente, o objeto da intuição sensível. ${ }^{8}$

Com vistas a entender o modo como Kant estabelece sua tábua de juízos, é importante realizar uma breve digressão, com vistas a estabelecer o porquê de a tábua dos juízos ser disposta necessariamente do modo que Kant a expõe. Devemos ter em vista que a concepção kantiana de juízo é devedora da lógica aristotélica. Aristóteles em seu De Interpretatione buscou estudar de maneira mais sistemática aquilo que foi por ele designado de logos apophântikos (frase declarativa), uma frase de estrutura "S é P" que descreve fatos do mundo; daí a pretensão de verdade da sentença, pois segundo Aristóteles seria através destas frases que se constituiriam nossos raciocínios sobre o mundo. Com isto em mente, Kant estabelece sua tábua dos juízos. Para o filósofo alemão, a diferença entre os juízos reside justamente em sua forma, que para Kant pode ser reduzida a quatro, a saber: qualidade, quantidade, relação e modalidade.

Tendo em mente a estrutura "S é P", a quantidade de um juízo incide sobre o sujeito através dos atributos todo (universal); algum (particular) e um (singular). A qualidade de um juízo por sua vez relaciona-se com o predicado através do qualitativos é $\mathbf{P}$ (afirmativos); não é $\mathbf{P}$ (negativos) e é não-P (infinitos). A relação por sua vez, funda-se com a cópula de modo a

\footnotetext{
${ }^{4} \mathrm{KrV}$ B 74

${ }^{5}$ A demonstração da apresentada por Kant na Estética Transcendental não será objeto de análise dessa pesquisa.

6 Ver PATON, 2008, p.243 ss; Michael Young. 'Funções do pensamento e síntese das intuições'. In: GUYER, 2009, pp.129-153; Rolf-Peter Horstmann. 'A Função Da Dedução Metafísica Na Crítica da Razão Pura de Kant'. In: Klein, Joel Thiago (Org.) Comentários às obras de Kant: Crítica da Razão Pura. Florianópolis: NEFIPO, 2012, pp.227-47.

${ }^{7}$ Proleg. IV: 304.

${ }^{8}$ Ver KrV B 75. É necessário dizer ainda algo sobre os juízos, a saber, da diferença entre a matéria e a forma dos juízos. A primeira refere-se aos "conhecimentos dados que se ligam no juízo para a unidade da consciência" (KANT, 2014, p.201); a segunda, por sua vez, consiste na "determinação da espécie e modo como as representações diversas pertencem como tais a uma consciência" (KANT, 2014, p.201).
} 


\section{Gabriel Martins Ferreira}

indicar a subordinação do predicado ao sujeito (categóricos); a subordinação do consequente ao fundamento (ou antecedente) (hipotéticos) e $a$ subordinação do membro da divisão ao conceito dividido (disjuntivos). A modalidade por sua vez diz respeito à pretensão de verdade do juízo, sendo que esta pretensão é tomada como possível (problemáticos), real (assertóricos) ou necessária (apodíticos). Eis o modo como é estabelecida, em linhas muito gerais, a tábua dos juízos na KrV B 95,

Fundamental é a definição de juízo dada anteriormente, pois ela traduz de maneira clara a função que possui o entendimento no processo do conhecimento, já que devemos ter mente que (I) o entendimento é a faculdade de pensar; (II) pensar é julgar; (III) julgar é basicamente unir representações; (IV) os diferentes modos como unimos as representações são as formas do juízo e (V) consequentemente a lista das formas do juízo fornecem os modos pelos quais o entendimento une as representações. Sob esse aspecto, acrescenta Kant;

A mesma função que dá unidade às diferentes representações em um juízo dá unidade também à mera síntese de diferentes representações em uma intuição e expressa em termos gerais, denomina-se conceito puro do entendimento. $\mathrm{O}$ mesmo entendimento, portanto, e por meio das mesmas ações pelas quais colocava em conceitos a forma lógica do juízo, introduz também... um conteúdo transcendental em suas representações, em virtude do qual elas são denominadas conceitos puros do entendimento... Desse modo, surgem exatamente tantos conceitos puros do entendimento... quantos eram, na tábua anterior, as funções lógicas em todos os juízos (KrV B 105).
$\mathrm{O}$ argumento aqui estrutura-se, em linhas gerais, mais ou menos da seguinte maneira: (I) o pensamento de objetos é um ato de espontaneidade do entendimento; (II) este ato do entendimento é um ato de ligação, ou na linguagem de Kant, uma síntese que confere unidade ao diverso oriundo da sensibilidade9; (III) Kant entende que existem condições para este ato de ligação, tais condições são responsáveis por conferir unidade ao múltiplo da intuição sensível para que este possa ser pensado como um objeto. Estas condições são as categorias do entendimento, isto é, os conceitos puros. ${ }^{10}$

Conforme apresentado acima o modo como Kant estabelece a tábua dos juízos e tendo em mente o que estabelecemos nos dois parágrafos acima, podemos apontar (ainda de maneira geral) o modo pelo qual a tábua das categorias é estabelecida, os quatro grupos cardinais, cada qual contento três categorias, são deduzidos da própria estrutura lógica do juízo de tipo "S é P". ${ }^{11}$ Assim, a Dedução Metafísica "busca exatamente comprovar uma suposição, a qual é uma condição de possibilidade de uma dedução transcendental, a saber, a suposição de que é realmente possível que conceitos a priori se refiram a objetos em geral"12, cumpre a tarefa à qual havia se proposto.

\section{A Dedução Transcendental Como Resposta} Parcial a Hume

Basicamente a função desempenhada pela Dedução Metafísica foi a de estabelecer quantos e quais são os conceitos puros do entendimento. Por Dedução Transcendental,

\footnotetext{
${ }^{9}$ Ver KrV B 103-104.

${ }^{10}$ De acordo com KrV B 128, acerca das categorias: "Elas são conceitos de um objeto em geral, por meio dos quais a intuição deste é vista como determinada em relação a uma das funções lógicas do juízo".

${ }^{11}$ Para uma discussão mais profícua a este respeito ver PATON, 2008, pp.295-96

12 Rolf-Peter Horstmann. 'A Função Da Dedução Metafísica Na Crítica da Razão Pura de Kant’. Trad. Joel Thiago Klein. In: Klein, Joel Thiago (Org.) Comentários às obras de Kant: Crítica da Razão Pura. Florianópolis: NEFIPO, 2012. PP-227-47.
} 


\section{Gabriel Martins Ferreira}

Kant entende a explicação do modo como esses conceitos podem referir-se a priori a objetos" (KrV B 117), o que significa dizer que o intuito da Dedução Transcendental é o de apresentar uma justificativa que legitime o uso das categorias. Conforme já explicado, o entendimento possui a função de conferir unidade ao múltiplo (o diverso) oriundo da sensibilidade, e que tal unidade é conferida através das categorias, portanto, a discussão agora não é a de provar que nossas intuições devem ser subsumidas as categorias (pois isso já foi feito na Dedução Metafísica), mas sim de explicar como isso acontece.

Com a Dedução Transcendental, interessa-nos sobremaneira apresentar o papel desempenhado pela unidade sintética da apercepção, bem como o caráter objetivo desta unidade. Para os objetivos desta pesquisa, concentrar-nos-emos em apresentar (I) a função desempenhada pela unidade sintética da apercepção e (II) o caráter objetivo desta unidade; e tal tarefa é executada por Kant nos parágrafos $\$ 16$ e $\$ 17$ da "Analítica dos Conceitos".

A unidade sintética da apercepção é apresentada de maneira consistente no parágrafo $§ 16$. Porém Kant já havia indicado a necessidade de tal ligação no parágrafo $\S 15$, que merece ser recuperada aqui, segundo Kant:

Ligação é a representação da unidade sintética do diverso.... Essa unidade, que antecede a priori todos os conceitos da ligação, não deve ser confundida com a aquela categoria de unidade, pois em juízos todas as categorias se fundam nas funções lógicas, mas nos juízos já é pensada a ligação, portanto a unidade de conceitos dados. A categoria já pressupõe assim uma conexão. (KrV B 131)
Esta unidade da qual Kant trata aqui é estabelecida por ele através da unidade sintética da apercepção, que no texto kantiano aparece na forma da proposição "Eu Penso".

O Eu Penso tem de poder acompanhar todas as minhas representações" isso - significa que se eu possuo consciência das representações, ainda que de modo préproposicional (ou "pré-juízo") - é o que faz com que tais representações possam efetivamente serem chamadas de minhas representações - é necessário tornar-se atualmente consciente destas representações enquanto minhas representações, em outras palavras, é preciso tornar-se consciente da unidade e identidade de um $\mathrm{Eu}$ como instância em que estas representações são representações e não outra coisa qualquer. ${ }^{13}$

O parágrafo $§ 17$ por sua vez, busca provar que esta unidade é uma unidade objetiva. Objeto na acepção kantiana é " aquilo em cujo conceito é unificado o diverso de uma dada intuição"14, e neste sentido Kant sustenta:

Mas toda unificação de representações exige unidade da consciência... consequentemente, a unidade da consciência é aquilo que unicamente constitui a relação das representações a um objeto, portanto a sua validade objetiva, por conseguinte que se tornem conhecimentos. O primeiro conhecimento puro do entendimento, portanto, em que se fundam todos os seus demais usos e que é também, ao mesmo tempo, inteiramente independente de todas as condições da intuição sensível, é, pois, o princípio da unidade sintética originária da apercepção (KrV B 137)

Assim a unidade sintética da apercepção, converte-se na condição de possibilidade de nosso conhecimento em geral (vale para qualquer objeto), mas não somente isso, uma

\footnotetext{
${ }^{13}$ Pedro Costa Rego. 'A Dedução Transcendental B: Objetivo e Método' In: Klein, Joel Thiago (Org.) Comentários às obras de Kant: Crítica da Razão Pura. Florianópolis: NEFIPO, 2012. P. 292. Ver também

$\mathrm{KrV}$ B 132.

${ }^{14} \mathrm{KrV}$ B 137
} 


\section{Gabriel Martins Ferreira}

vez que a unidade sintética da apercepção é o que faz com que o múltiplo seja subsumido às categorias fazendo dele um objeto (portanto, uma representação para um sujeito segundo uma síntese). Esta unidade da apercepção é também a responsável por fazer com que todos os fenômenos estejam sempre concatenados segundo leis. ${ }^{15} \mathrm{O}$ sistema de fenômenos ligados segundo leis, ou seja, segundo as categorias, é chamado por Kant justamente de natureza.

Destas duas considerações, já nos é possível apresentar uma resposta para a objeção de Hume, que pregava a impossibilidade de uma ciência a priori da natureza, pois estabelecemos que a unidade sintética da apercepção é o que propriamente confere unidade a todas as minhas representações e é ela também a responsável por ligar todos os fenômenos segundo leis.

Após a exposição de alguns pontos centrais da Dedução Transcendental, temos condições de oferecer uma resposta parcial a Hume, pois o que acabamos de expor é que Kant não está disposto a aceitar a tese humeana de basear nosso conhecimento da experiência em princípios psicológicos ou subjetivos, pelo contrário, Kant intenta garantir a objetividade do conhecimento da natureza provando a validade a priori de certas regras, de modo que o resultado do conhecimento dos fenômenos ou da natureza seja possível necessária e universalmente, e não apenas como fruto de verossimilhança, tal como quer Hume. O argumento kantiano é contundente, pois de acordo com Kant se não for possível, ou ainda, se não for necessário que um conteúdo empírico qualquer seja subsumido a uma regra do entendimento, tal conteúdo não seria sintetizável e dessa forma não poderia ser um conteúdo para a consciência, para o "Eu penso". ${ }^{16}$ De modo que a tese que sustenta toda esta argumentação - e valho-me mais uma vez das palavras de Andrea Faggion - ,qual seja, a de que "a própria forma dos juízos, a identidade do eu, dependeria da possibilidade de síntese dos conteúdos cognitivos, de modo que a associabilidade desses conteúdos não poderia ser uma matéria de sorte deixada ao acaso". ${ }^{17}$

O próximo passo para oferecer uma resposta definitiva a Hume seria demonstrar que a causalidade não é fruto de uma associação psicológica irrefletida e sim um princípio racional. Isto será objeto de argumentação nas "Analogias da Experiência" onde Kant vai demonstrar que a causalidade é o que confere a "união sintética das percepções em uma consciência em geral" 18 , sendo que a subordinação dos eventos à lei de causalidade é o que torna possível que tais eventos possam ser tomados como objetos de experiência. ${ }^{19}$

\section{Considerações Finais}

Chegamos assim, ao propósito desta pesquisa, qual seja "como seria possível uma metafísica como ciência após a objeção de Hume? ". A tese que buscou-se sustentar ao longo deste projeto foi a de que, embora Kant concordasse com a objeção interposta por Hume, qual seja,

\footnotetext{
15 PATON, 2008, p.412. KrV A 108.

${ }^{16}$ Esta argumentação encontra-se na KrV A 121-122. Ver também a explicação de Andrea Luisa Bucchile Faggion, Op. Cit. pp. 380-383.

17 Op. Cit, p. 384

${ }^{18}$ Ver Prolegômenos $\$ 29$.

${ }^{19} \mathrm{KrV}$ B 234.
} 


\section{Gabriel Martins Ferreira}

a de que através de procedimentos meramente lógicos a metafísica jamais poderia obter um conhecimento da realidade, porém isto não significaria que a metafísica não seria possível de outro modo, a saber, a metafísica segundo uma disposição natural da razão humana, tal como a entende Kant, ainda que não nos sirva para trazer nenhuma ampliação do ponto de vista cognitivo, serve antes como uma disciplina da razão, que busca justificar o espaço de uso, por assim dizer, dos conceitos e princípios, bem como de estabelecer a partir deles as condições de possibilidade das ciências - no caso da $\mathrm{KrV}$, nomeadamente a matemática (Estética Transcendental) e a física newtoniana (Analítica Transcendental) - ou nas palavras do próprio Kant, a metafísica "enquanto consumação de toda cultura da razão humana, deve servir de fundamento a possibilidade de algumas ciências e ao uso de todas"20 $^{20}$

\section{Referências Bibliográficas}

ALISSON, H. Kant's Transcendental Idealism. New Haven and London: Yale University Press, 1983.

GUYER, P. (org.) Kant. Trad. Cassiano Terra Rodrigues (Tradução da Coleção Cambridge Companion). São Paulo: Editora Ideias e Letras, 2009.

HUME, D. Investigações sobre o entendimento humano e sobre os principios da moral. São Paulo: Editora UNESP, 2004.KANT, I. Crítica da Razão Pura. Trad. Fernando Costa Mattos. São Paulo: Editora Vozes, 2013.
Prolegômenos a qualquer Metafísica futura. Trad. José Oscar de Almeida Marques. Editora Estação Liberdade, 2014.

KLEIN, Joel Thiago (Org.) Comentários às obras de Kant: Crítica da Razão Pura. NEFIPO,2012. Disponível in: http:// www.nefipo.ufsc.br/files/2012/11/ comentarios1.pdf <acesso em $21 \mathrm{de}$ fevereiro de 2016>

PATON, H. J. Kant's Metaphysic of Experience. II Vols.: London: Candler Press, 2008

\footnotetext{
${ }^{20} \mathrm{KrV}$ B 879
} 